\title{
Science and Health in the Present Moment of Humanity
}

\section{Jesús Verdecia Tamayo MD*}

Department of Social Science \& political Science, Granma University, Cuba

*Corresponding author: Manuel de Jesús Verdecia Tamayo, Department of Social Science \& political Science, Granma University, Cuba, Tel: 53023572497; 53023572157; Email: mverdeciat@udg.co.cu

\section{Editorial}

Volume 4 Issue 3

Received Date: June 25, 2021

Published Date: July 12, 2021

DOI: $10.23880 /$ abca-16000186

\section{Editorial}

Although since the emergence of the human species, and with it of thought, there has been a continuous search for explanations and solutions to the multiple and diverse health problems that have permanently affected humanity, today the importance of science is more remarkable, or science, and scientific production for human health.

At the present time, societies, in one way or another, face the most serious pandemic in the last 100 years [1,2]; also called the first world "biological" war [3]. COVID-19 produces multiple effects: biological at the individual level, to profound social, economic and political repercussions. Precisely, given its marked negative impact, the promotion of biological, epidemiological, social, economic research and the rest of the fields of knowledge are required.

This problem makes visible, in the foreground, the issue of safeguarding one of the most precious universal public goods: people's health and well-being [1]. Therefore, the starting conditions of the different societies as well as the levels of social equity or inequalities, the differentiated attention to specific social groups such as girls and boys, youth, the elderly or women and, especially, the characteristics and scope of the health systems, constitute social strengths or weaknesses in the face of the pandemic. Today, scientific capacity is highlighted as a component of high value for human, social, economic and technological development.

Currently, health research is a top priority as a way to improve performance, the results of health systems, and the need to apply scientific advances effectively, equitably, and rationally in social practice. The link between scientific research for health, with social development, its peculiarities and its successes, especially the harmonious and balanced fusion of all research modalities in medical practice is undeniably demonstrated.

But the nexus between science and health occurs in a complicated relationship in that scientific-technical progress leads to a unilateral intellectual development, making scientists, for the most part, ignorant of other areas in general, including health. On the other hand, health, as a social category, constitutes one of the most dynamic and complex phenomena that man and society face.

The development of science, scientific knowledge and the high level of available resources and technologies allow a greater understanding and explanation of health in its components and determinants as well as in its relationships and dynamics. In the approach to health, from a scientific perspective, multiple disciplines converge that increase over time and that, somewhat conventionally have been grouped into the so-called basic sciences: to name those that, fundamentally at the expense of laboratories equipped with high technologies, are oriented to the structures and functions of the most "elementary" levels of life and penetrate to unexpectedly tiny and complex worlds.

Also biomedical research to study aspects related to man, his organs and tissues, with a predominantly clinical approach and research in health, public health or socio medical to address the most general, population and comprehensive aspects of the health-disease process and its factors determinants. In this way, research and researchers, and even science itself, have been divided and separated into fields, areas, institutions and organisms, which have allowed specialization, development and deepening in scientific work, and favored comprehensiveness, synergy and desirable rationality in the search for a paradigm shift 
that expands "health research" and encompasses all sectors involved in "health research".

The nexus between science and health occurs in a unique dynamic between social need, especially in health, scientific production and its introduction into medical practice. This dynamic is complex and multi-causal, as it constitutes a strong impulse for international collaboration and cooperation, given that global health problems worsen every day. In addition, this relationship demands a strategic approach that improves the stewardship of research and strengthens the essential functions of public health within a policy of scientific research and applied results in health.

Health, in its evolution, has become a human right, due to the complexity of health problems and phenomena, research is essential to improve it, as an integral part of society and the economy. The globalization of processes accelerates new knowledge about human biology and the revolution in technologies and information, issues that present new challenges and opportunities for this field. Scientific, social and health asymmetries, in countries and between them, grow as threats and risks also grow: climatological, economic, social and political that create the new conditions, immersed in which are health and science, as well as the systems that promote, protect, recover, improve and investigate it.

Thus, the strengthening and leadership of national research systems for health and international cooperation is vital to face health challenges in a context of inequity, for the fulfillment of the Millennium Goals, climatic, epidemiological, demographic changes, food crises and other conditions that disadvantage countries, particularly the poorest. The leadership of national health research systems is a matter of the State and must be actively exercised through the ministries of health, with the support of other State actors and society. It is the only way to articulate research and innovation with the priorities of social development and public health, and to guarantee consistency in the allocation of funds and the formation of resources for research.

The limitations of the countries in terms of knowledge, financing and technology must be the object, more and more of international technical cooperation and take into account that health challenges can be transformed into opportunities through technological and social innovations that are not necessarily very expensive . For the national research systems that contribute to health to be sustainable, a coordinated strategy of education and training of human resources is required. But researchers must be trained by working on projects related to the priorities of the system. Training must be comprehensive and articulate with the productive sector. Research teams must be multidisciplinary, stable and continuous over time.
The management of research, financing, the training of researchers, the processes and methodologies to define priorities, multicenter approaches, the close link between science and practice or research-economy-society, the insertion of research in the work of services health and academic training, international collaboration, are essential features for the development of health research systems. Currently, the results highlight that the relationship between science and health has contributed to the construction of the knowledge base that has become a reference and support to the management of States and Governments in the confrontation with health problems, especially the current COVID-19 pandemic.

The articulation between science and health, with their contributions, have generated an important scientific activity that is expressed in the actions undertaken, the number of publications of scientific articles, both in magazines and other national and international media. They have experienced remarkable growth, providing valuable solutions in a time of enormous complication; they have strengthened their ties with their object of study: society, with the various economic, political and social actors, especially with decision-makers; in essence, their participation and contribution has been substantive. The foregoing shows the importance of the human potential created in all fields and areas of science, especially in health sciences, which contribute not only in the technical field for the effective confrontation of the pandemic, but also carry a high degree of humanism with their technical skills and values, which allows them to achieve high social recognition. In such a way that they contribute to the development of the society under study and, at the same time, contribute to transform, asserting decision-making based on a critical sense and responsibility.

\section{References}

1. Bárcena, A (2020) Zero Hour: Our region in the face of the pandemic. Economic Commission for Latin America and the Caribbean.

2. Ochoa-Alonso A, Selva-Suárez L, De Souza LE (2020) Science, health and solidarity to save lives: a call to action against COVID-19. Anales de Ciencias de Cuba 10(2).

3. Caldera-Ynfante JE (2020) Biocracy and fundamental right to the new world order in the post COVID-19 pandemic. Utopía y Praxis Latinoamericana 25(4): 3349. 